\title{
Arthroscopic Treatment of Septic Arthritis of the Shoulder: Decision-Making for Reoperation
}

\author{
Yong-Min Chun \\ Department of Orthopedic Surgery, Arthroscopy and Joint Research Institute, Severance Hospital, Yonsei University College of Medicine, Seoul, Korea
}

Septic arthritis is a devastating disease requiring urgent surgical treatment and systemic antibiotics administration. As noted in the literature, degradation of cartilage occurs through cytokines, bacterial endotoxins, and other destructive enzymes invoking the host immune system [1,2]. This catastrophic cascade is likely to end with irreversible damage to the cartilage. Septic arthritis can even spread into the bone causing osteomyelitis. With recent advancements in arthroscopic techniques and devices, arthroscopic debridement and irrigation have become more popular and are regarded as the first-line treatment option rather than conventional open arthrotomy [3,4]. An arthroscopic approach provides better visualization of the joint and better preserves range of motion (ROM) and affected joint function as a minimally invasive approach. Several studies have reported satisfactory outcomes with arthroscopic debridement and irrigation $[1,5,6]$. Nonetheless, the rate of reoperation after arthroscopic debridement remains as high as $26 \%$ to $32 \%[1,5,6]$.

In "Arthroscopic treatment of septic arthritis of the shoulder: technical pearls to reduce the rate of reoperation" by Kwon et al. [7], although there was no comment on the development of post-infectious arthritis in the affected shoulder, Jeon et al. [5] described their clinical experience with 36 patients who underwent arthroscopic debridement for septic arthritis. They sought to pro- vide technical tips in order to reduce the reoperation rate and to achieve satisfactory shoulder functional scores and ROM. Interestingly, just two patients underwent reoperation, which is a much lower recurrence rate than reported in previous studies addressing septic arthritis in the shoulder joint $[1,5,6]$. The indications for reoperation in their study were: (1) failure of wound drainage output and C-reactive protein (CRP) level to decrease, or (2) evidence of persistent infection on postoperative magnetic resonance image (MRI).

On the other hand, Kim et al. [1] reported that reoperation should be considered when (1) decreasing CRP level increases again, (2) a 7- to 10-day plateau in the decrease of the CRP level, or (3) failure of postoperative wound drainage output volume to decrease. The authors [1] also suggested that persistent elevation of CRP should be an indication for reoperation. Although some authors proposed persistent pain with local warmth and limitation of motion or persistent infection on postoperative MRI as indications of reoperation, I do not think these measures are objective. Furthermore, it is difficult to differentiate resolution of infection from persistent infection on postoperative MRI. Even after the infection resolves and CRP returns to normal, soft tissue or synovium can be enhanced on gadolinium-enhanced MRI and this finding is non-specific $[5,8]$. Thus, CRP level can be an important and objec-

Received: February 6, $2020 \quad$ Accepted: February 13, 2020

Correspondence to: Yong-Min Chun

Department of Orthopedic Surgery, Arthroscopy and Joint Research Institute, Severance Hospital, Yonsei University College of Medicine, 50-1 Yonseiro, Seodaemun-gu, Seoul 03722, Korea

Tel: +82-2-2228-5679, Fax: +82-2-363-6248, E-mail: min1201@hanmail.net, ORCID: https://orcid.org/0000-0002-8147-6136

IRB approval: None.

Financial support: None.

Conflict of interest: None.

Copyright@ 2020 Korean Shoulder and Elbow Society.

This is an Open Access article distributed under the terms of the Creative Commons Attribution Non-Commercial License (http://creativecommons.org/licenses/by-nc/4.0/) which permits unrestricted non-commercial use, distribution, and reproduction in any medium, provided the original work is properly cited. 
tive indicator for reoperation. Another objective indicator for reoperation can be wound drainage output volume failing to decrease [1]. Aside from CRP level, I think that reoperation should be considered if wound drainage output does not decrease.

Lastly, one further question should be considered: should reoperation be performed as aggressive open arthrotomy? Although it may depend on surgeon preference, in the context of significant bone lesions present at advanced stages, I think an open arthrotomy would be better rather arthroscopic approach. Kwon et al. [7] indicated that to reduce the reoperation rate in septic arthritis, the use of a posterolateral portal, a $70^{\circ}$ scope in the subacromial space, a large volume of irrigation ( $>20 \mathrm{~L}$ ), and multiple suction drains after surgery are recommended.

\section{REFERENCES}

1. Kim SJ, Choi YR, Lee W, Jung WS, Chun YM. Arthroscopic debridement for septic arthritis of the shoulder joint: post-infectious arthritis is an inevitable consequence? Arch Orthop Trauma Surg 2018;138:1257-63.

2. Riegels-Nielson P, Frimodt-Möller N, Jensen JS. Rabbit model of septic arthritis. Acta Orthop Scand 1987;58:14-9.

3. Kim SJ, Choi NH, Ko SH, Linton JA, Park HW. Arthroscopic treatment of septic arthritis of the hip. Clin Orthop Relat Res 2003;(407):211-4.

4. Peres LR, Marchitto RO, Pereira GS, Yoshino FS, de Castro Fernandes M, Matsumoto MH. Arthrotomy versus arthroscopy in the treatment of septic arthritis of the knee in adults: a randomized clinical trial. Knee Surg Sports Traumatol Arthrosc 2016;24:3155-62.

5. Jeon IH, Choi CH, Seo JS, Seo KJ, Ko SH, Park JY. Arthroscopic management of septic arthritis of the shoulder joint. J Bone Joint Surg Am 2006;88:1802-6.

6. Abdel MP, Perry KI, Morrey ME, Steinmann SP, Sperling JW, Cass JR. Arthroscopic management of native shoulder septic arthritis. J Shoulder Elbow Surg 2013;22:418-21.

7. Kwon JE, Park JS, Park HB, et al. Arthroscopic treatment of septic arthritis of the shoulder: technical pearls to reduce the rate of reoperation. Clin Shoulder Elbow 2020;23:3-10.

8. Graif M, Schweitzer ME, Deely D, Matteucci T. The septic versus nonseptic inflamed joint: MRI characteristics. Skeletal Radiol 1999;28:616-20. 